\title{
MODELOS DE ACOMPANHAMENTO JORNALÍSTICO DA POLÍTICA EM PORTUGAL
}

Renato Ferreira

Ricardo Jorge Pinto

\section{Resumo}

De que forma se faz Jornalismo Político em Portugal? E de que forma se podia fazer, melhorando-o? Partindo de uma análise quantitativa e qualitativa a 3 jornais diários ditos de "referência" portugueses saídos nos dias de campanha das Presidenciais 2011, tentaremos teoricamente esboçar um modelo explicativo de como a Política - neste caso em campanha - é acompanhada pelos media (em particular aqui pelos jornais), para depois, no final, esboçarmos um modelo abstracto de hipotético acompanhamento, apresentando soluções concretas para esse efeito.

Palavras-chave: Jornalismo; Política; Modelos; Jornais; Presidenciais.

\begin{abstract}
How does we make Political journalism in Portugal? What can be done to improve it? From a quantitative and qualitative analysis to three reference Portuguese newspapers that came up in the campaign days during the Presidencies 2011 in Portugal, we will try to theoretically draw an explicative model of how Politics - in this case in politics on campaign - is covered by media (in particular by newspapers), to then, in the end, try do draw an abstract model of possible (better) coverage, giving concrete solutions to that effect.
\end{abstract}

Keywords: Journalism; Politics; Models; Newspapers; Presidentials.

\section{Introdução}

Analisamos três jornais diários generalistas portugueses ditos de 'referência' - o ' $i$ ', o 'Público' e o 'Diário de Notícias' - durante a campanha para as Presidenciais 2011 em Portugal, para tentarmos confirmar a seguinte hipótese: o modelo de acompanhamento jornalístico que se faz em Portugal é 'horizontal'. E o que é que compreendemos como 'horizontal' neste trabalho? O fato de poucas ideias de cada um dos candidatos ser 'extraída' deles e haver um maior enfoque no confronto/combate (horizontalidade) entre os candidatos em vez de um maior desenvolvimento por parte dos media de cada uma das visões de cada um dos candidatos (o que seria um acompanhamento 'vertical').

O que faremos para confirmar ou não a nossa hipótese? Uma notícia é construída tendo em conta alguns critérios, para os quais olhamos como preferenciais e prioritários em relação ao que queremos sublinhar no veicular de algo. Mais concretamente, neste estudo, utilizamos cinco categorias - 
'Temas', 'Política', 'Combate', 'Estudos' e 'Campanha' - como potenciais prioridades do jornalista ao transmitir a notícia da campanha do candidato político, sendo que a unidade análise são os títulos das notícias, primeiro, e depois os '/eads' das mesmas.

Advogamos neste trabalho, caso se verifique a hipótese - ou seja, se a categoria 'Combate' for a mais utilizada -, que a 'verticalidade' seria mais benéfica para uma maior conscientização do cidadão comum no que a vida política diz respeito, defendendo-se - uma vez que os media não nos dizem 'o que' pensar mas 'sobre o que' pensar (como nos fala a teoria do agendasetting) - que os media nos faça pensar sobre as políticas que de fato interferem no cotidiano de todos nós (a 'Policy) em vez de carregar e sublinhar constantemente as críticas 'horizontais' entre agentes políticos que, nesta percepção que os media passam à opinião pública, jogam constantemente jogos de poder incessantemente em busca das lideranças políticas (o que entendemos que se passa efectivamente, mas cuja projecção é demasiada quando comparada com os verdadeiros temas que distinguem candidatos e partidos).

Esta hipótese pode por em causa a percepção da 'culpa' - se é que ela é de alguém - da má fama dos políticos e da política em geral, uma vez que este artigo visa também incluir o papel dos jornalistas e do jornalismo na imagem que a população ganha do que os agentes políticos fazem no decorrer do seu trabalho: se essa imagem que passa não é a real - ou seja, não corresponde à efetiva contribuição de tais actores da sociedade - teremos então uma imagem enviesada de tal classe profissional. Neste artigo, contudo, não nos pomos ao lado de ninguém, defendendo ou atacando seja quem for - apenas tentamos objetiva e racionalmente obter uma imagem concreta de como as notícias sobre política estão a ser construídas em Portugal (mormente nos jornais analisados).

\section{Método}

Primeiro, explicaremos a organização política em Portugal. Mais concretamente a forma como funciona o sistema de governo - semipresidencialismo - , para compreendermos a base que os media têm que veicular e a importância do Presidente da República neste país.

Depois, uma contextualização sobre a relação entre media (ou Jornalismo, neste caso) e políticos e uma breve explicação da teoria do 'agenda-setting', sem esquecer o que está na base da nossa hipótese inicial a personalização crescente da política, partiremos para a análise aos jornais já referenciados, analisando o que está na base da construção das notícias. Para isso, atentamos aos títulos e leads de todas as notícias destes jornais saídos em campanha relativos à mesma, na cobertura dos candidatos Aníbal Cavaco Silva, Manuel Alegre, Fernando Nobre, Defensor Moura, Francisco Lopes e José Manuel Coelho. Na base da construção das notícias, e seguindo a metodologia de Salgado (2007), estão 5 categorias possíveis: 'Temas' - 
quando os títulos e leads nos davam conta de determinados assuntos trazidos à discussão (e às notícias) pelos candidatos; 'Combate' - quando as notícias eram construídas tendo como foco principal as críticas (horizontalidade) dos candidatos entre si; 'Estudos' - quando as sondagens feitas durante a campanha tiveram eco nestas notícias; 'Política' - quando os títulos e leads nos indicavam apoios que os candidatos tinham, ou suas estratégias ou apelo ao voto e à não abstenção; e finalmente 'Campanha' - quando os elementos analisados das notícias se referiam às ações diretas e acontecimentos relacionados com a dinâmica das campanhas (como a muita ou pouca adesão nas arruadas, comícios, jantares, etc).

Caso se verifique que a categoria mais presente seja a categoria de 'Combate', a nossa hipótese inicial estará comprovada. A ocorrência das outras categorias irão dar imagem real e fidedigna da base de construção de notícias em jornais, em Portugal.

\section{O sistema de governo em Portugal}

Portugal tem como sistema de governo o Semi-Presidencialismo (SP). Mas afinal, o que é, na prática, isto do SP? Entender isto poderá trazer alguma luz às posteriores preocupações deste trabalho de mostrar como se acompanha jornalisticamente a política, mormente ajudar-nos-á a entender o tipo de eleição que analisamos: Presidenciais. "O SP é uma mescla de presidencialismo e de parlamentarismo" (FERNANDES, 2008, p. 154). Segundo este autor, o esquema institucional deste sistema de governo é muito parecido com o do sistema parlamentar, uma vez que em ambos existem um Chefe de Estado e um Chefe do Governo; e em ambos os sistemas, também, o Executivo governa apenas se tiver a confiança do Parlamento. Mas, obviamente, não podiam existir só semelhanças: no SP o Chefe de Estado (o Presidente da República - PR), que é eleito por sufrágio universal (como no presidencialismo), não tem apenas - como acontece no parlamentarismo - funções representativas, simbólicas, mas também amplos poderes (não tantos quanto no Presidencialismo) sem contudo ser responsável, nas suas decisões políticas, perante o parlamento. Fernandes considera mesmo o Chefe de Estado como "o elemento central do sistema" (FERNANDES, 2008, p. 154). O Governo, esse, depende da confiança quer do $\mathrm{PR}$ quer do parlamento.

Mas quanto aos poderes do "elemento central do sistema", eles são poderes constitucionais significativos. Até porque ele partilha o poder executivo com um Primeiro-Ministro. Tendo Portugal deixado de ser uma ditadura em 1974 ( 25 de Abril), ele - o SP - entrou em vigor (nasceu) pelas mãos da Constituição de 1976 que foi aprovada a 2 de abril. Aí terá nascido a "matriz portuguesa" do SP (NOVAIS, 2007, p. 264).

Para compreendermos então melhor esta configuração específica, recorramos a Carvalho (2010, p. 90-91) que resume bem todas as características que precisamos aprender neste artigo sobre este sistema de 
governo, para já características não apenas aplicáveis a um só país mas a todos que adoptam o SP. Em todos eles se verificam os 8 pontos que a seguir apresentaremos parafraseados:

1. Chefe de Estado, Governo e Parlamento são os três órgãos políticos com poderes reais (nos aparentemente semipresidenciais os poderes do PR são próximos dos Chefes de Estado no parlamentarismo);

2. Chefe de Estado é eleito por sufrágio universal e direto, tal como o Parlamento (nos casos da Irlanda e Islândia, sempre que há apenas um candidato presidencial, dispensam-se eleições);

3. Chefe de Estado tem poder efetivo de dissolução parlamentar. Pode fazê-lo por decisão própria, para além de qualquer proposta do governo que estiver em funções e sendo mesmo uma decisão contra a vontade deste;

4. Há uma diarquia do executivo, em que Chefe de Estado e Chefe de Governo têm funções distintas;

5. Chefe de Estado com funções de fiscalização, supervisão e regulação do sistema de governo (que variam de país para país), o que the permite controlar a atividade do Governo;

6. Chefe de Estado com atos que necessitam de referendo ministerial em coexistência com outros que não necessitam;

7. Governo é formado em função dos resultados eleitorais e a sua cosntituição e sobrevivência dependem da confiança parlamentar;

8. Governo é sempre responsável politicamente perante a Câmara representativa, e em alguns países perante o Chefe de Estado também.

Quando falamos de jornalismo político, falamos de acompanhar cotidianamente, para informação do público/receptor/cidadão, a relação/ligação entre Presidente, Governo e Parlamento - relação estipulada pelo SP -, embora o acompanhamento jornalístico da política não se esgote nestes três órgãos de soberania: a oposição, os sindicatos, a sociedade civil, economistas, comentadores/opinion-makers, etc., são elementos sempre em jogo no jogo do jornalismo político, até porque a política abrange toda uma sociedade e seus elementos e o jornalismo quer dar conta de toda a complexidade que está inerente ao seu objeto de estudo/atenção. Ponhamos então, neste trabalho e agora, o jornalismo em relação com esta realidade política que compreendemos anteriormente.

\section{Os media, a política e os cidadãos}

"A política é uma regulação das relações de visibilidades", escreveu Daniel Innerarity (2002, p. 147), acrescentando que:

Nas sociedades tradicionais, entre os privilégios do poder está um privilégio de atenção activa: ver todos sem poder ser visto ou sem ter de ser visto. Para a carreira política 
moderna, pelo contrário, a chave consiste em dispor de um privilégio de atenção passiva: ser visto por todos sem poder ver ou sem ter de ver. Um emir contemporâneo já não necessita de se disfarçar: todas as tardes pode visitar os seus domínios para ser reconhecido sem o inconveniente do contacto imediato com a população.

E tudo isto graças a quê? Aos meios de comunicação, que "são [...] os actuais distribuidores das relações de visibilidade" (INNERARITY, 2002, p. 147). Concordando com este autor e com uma realidade visível e presente a toda a população, está Salgado quando escreve que (2005, p. 86) "os media audiovisuais e eletronicos, através das suas características técnicas e da visibilidade que permitem, contribuíram para encenar um outro tipo de autoridade política", ao contrário da, por exemplo, autoridade dos reis em tempos de monarquias absolutas, que é a autoridade "que se faz pela proximidade, pela crença de que quem governa é alguém como nós, que está próximo e de quem podemos observar as suas características mais pessoais" (SALGADO, 2005, p. 86).

Esta mediatização da vida política, isto é, "a utilização intensiva e regular, por parte da classe política, da imprensa, da rádio e, sobretudo, da televisão [sem esquecermos a Internet, acrescentamos nós]" (RIEFFEL, 2003, p. 11), não será algo, segundo este autor, que resuma a política, pois esta não é apenas a arte de comunicar e o efeito de anúncio, embora "muitas das decisões tomadas pelos governantes dependem, hoje em dia, do modo como os media e, nomeadamente, os jornalistas falam deles" (RIEFFEL, 2003, p. 11). O jornalismo (ou os media) justifica assim, e segundo o referido anteriormente, a designação de "quarto poder" que Ihe imputaram: o poder vigilante dos três poderes fundacionais do estado democrático-liberal - o executivo, o legislativo e o judiciário. Conforme nos ajuda a perceber Oliveira (2007, p. 21 e 169), a designação 'quarto poder' é por alguns estudiosos atribuída a Edmund Burke (1729-1797), que a terá utilizado no final do século XVIII para se referir ao poder político que a imprensa possuía em relação aos três poderes de então no contexto britânico - os Lordes, a Igreja e os Comuns -, sendo o mais importante dos quatro; é por outros estudiosos atribuída a Thomas MacCaulay, deputado do Parlamento inglês que, em 1828 terá apontado para a galeria onde estavam os jornalistas, tendo-os apelidado com essa designação; e pela opinião do historiador William Safire, excomentarista político do New York Times, falecido em 2009, a expressão terá entrado na história pelas mãos do ensaísta William Hazlitt, em 1821, quando este se referiu ao jornalista William Cobbet e seu estilo ( 3 Williams envolvidos nesta potencial história explicativa).

Para Mesquita, esta invocação do jornalismo enquanto poder "conduz, aliás, a resultados perversos do ponto de vista da afirmação da legitimidade da presença do jornalista no espaço público" (2003, p. 72). Isto porque, se os media estivessem de fato em plano idêntico aos poderes republicanos de 
Montesquieu, se poderia colocar a questão "Quem vos elegeu?", ou então "Será necessário um quinto poder para controlar o quarto?". Por esta razão, este autor prefere e defende a ideia do jornalismo contra-poder; esta ideia, diz ele, "é invocada na actualidade com maior frequência do que a fórmula datada do «quarto poder»", e terá maior pertinência "porque se revela dotada de maiores virtualidades enquanto modo de afirmação dos profissionais de jornalismo no espaço público" (MESQUITA, 2003, p. 74). Aqui, nesta perspectiva, os media, ou o jornalismo, ou as instituições de imprensa, como ele the chama, são encaradas como integrando o sistema de pesos e contrapesos característico dos regimes democráticos.

No entanto, há quem discorde de ambas as designações: Augusto Santos Silva, por exemplo. Num artigo no jornal 'Público' de 08 de Novembro de 2003, referenciado por Barriga (2007, p. 15), aquele autor escreveu que é tão errado chamar os media de quarto-poder quanto de contra-poder. Para ele, eles são um poder efetivo, que se exerce por si só. Têm "não apenas poder de informação (proporcionando às pessoas os elementos de conhecimento que lhes permitam construir interpretações), mas um poder de formação (modelação das maneiras de ver, conhecer e avaliar o mundo)"; será ainda um poder não apenas de influência, "mas um real poder de conformação, que produz realidade, que faz e desfaz agendas, manifesta ou esconde factos, promove ou castiga protagonistas".

\section{A teoria do 'Agenda-Setting'}

João Marcelino é peremptório, num artigo de opinião do dia 15 de janeiro de 2011 no 'DN' (não a propósito das presidenciais, mas a propósito de um trabalho de investigação que o jornal fez sobre o Estado): "vale a pena o jornalismo ter uma agenda própria e colocar-se sem reserva do lado da cidadania, vivida esta sem qualquer intenção de protagonismo político", rematando depois esta ideia escrevendo "aos jornalistas o que é do jornalismo e aos políticos o que é da política". Será que esta distinção pode ser feita de forma assim tão estanque? O esquema que se segue dá-nos uma ideia clara de como a agenda política, a mediática e a pública se relacionam entre si. 
Figura 1 - O processo de agendamento segundo Rogers, Dearing e Bregman (1988)

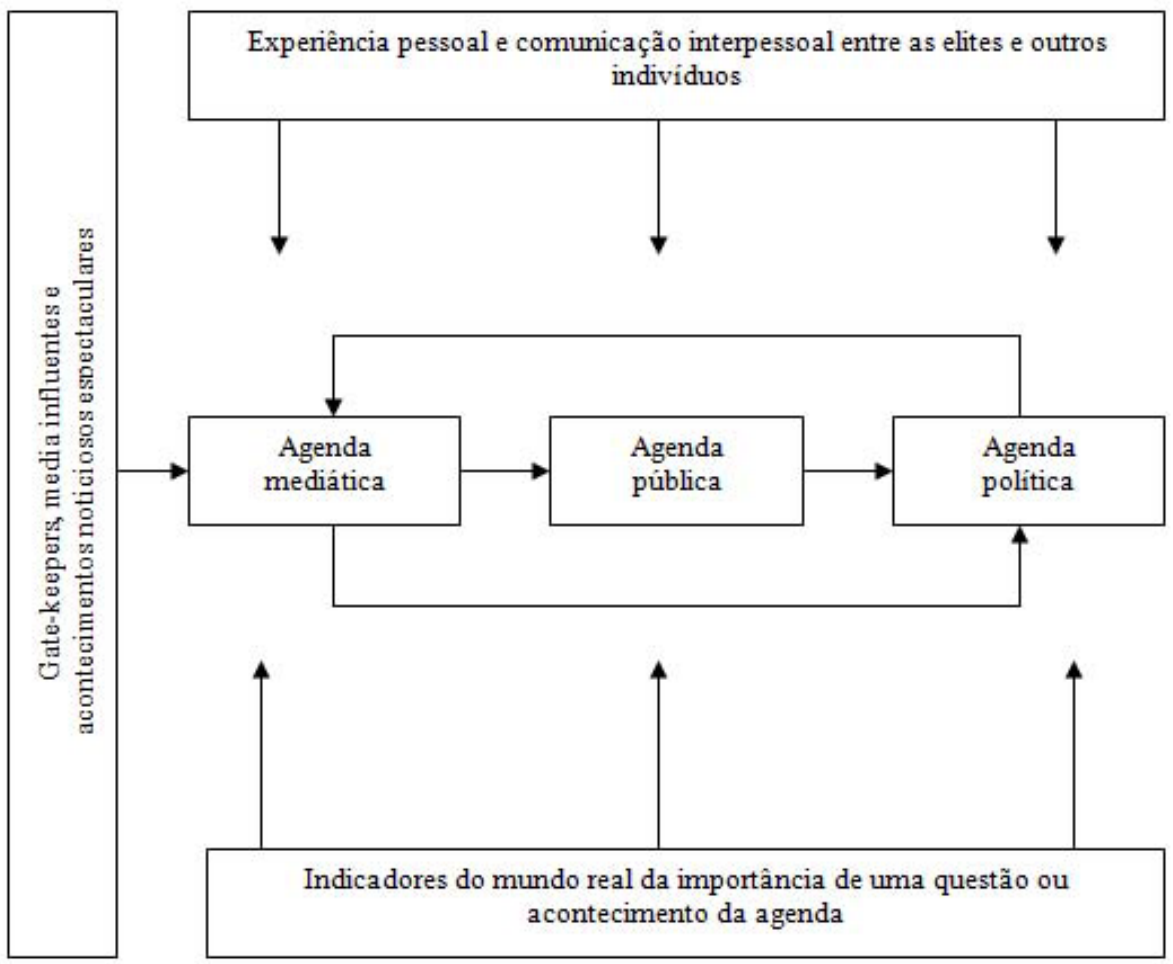

Fonte: Sousa (2008, p. 11).

Este esquema está presente num artigo de Sousa, investigador em Comunicação, que diz que pode-se assim observar que "a agenda mediática influencia a agenda pública e a agenda política, conforme teorizado no texto fundador de MacCombs e Shaw (1972)" (SOUSA, 2008, p. 10). Estes dois autores referenciados, pioneiros na apresentação da hipótese do agendamento [agenda setting], ao tratar deste tema, confirmam que os media têm a capacidade de influenciar a projeção dos acontecimentos na opinião pública, o que vai fazer com que seja estabelecido "um pseudoambiente" fabricado e montado pelos meios de comunicação. Este estudo tinha como essência algo que Walter Lipmann tinha dito já em 1922 no seu "Public Opinion", em que o autor menciona o modo como as pessoas chegam a conhecer o mundo exterior e a sua própria existência, como formam as imagens em suas mentes e seriam os meios de comunicação que constroem essas imagens ao seleccionar e organizar símbolos de um mundo que nos rodeia; que Park tinha dito em 'The city' em 1925 - "que notava que os meios de comunicação definiam uma certa ordem de preferências temáticas" (BARRIGA, 2007, p. 3); e em "Long, que enunciara claramente a hipótese do agendamento temático" (BARRIGA, 2007, p. 12); sem esquecermos a frase 
emblemática de Cohen, escrita em 1963, que dizia "embora a imprensa, na maior parte das vezes, possa não ser bem sucedida ao indicar às pessoas como pensar, é espantosamente eficaz ao dizer aos seus leitores sobre o que pensar" (1963, apud BARRIGA, 2007, p. 12).

Voltando, contudo, ao esquema apresentado anteriormente, também é certo que a agenda política "também influencia a agenda mediática, permeável, de resto, à influência de promotores de notícias (segundo o conceito de Molotch e Lester, 1974), que, em vários casos, são agentes políticos" (SOUSA, 2008, p. 10). Quanto à agenda pública, segundo este autor e o esquema apresentado, ela também pode influenciar diretamente a agenda política. As três agendas serão modeladas, quanto às temáticas e a importância de cada um dos temas, pela comunicação interpessoal que as pessoas estabelecem entre si, também pela experiência pessoal que cada um de nós tem do mundo e pelos acontecimentos que ocorrem no mesmo.

O modelo de 'Agenda-setting', que ainda hoje é tratado como uma hipótese, é em si algo que denota a importância dos temas, dos assuntos, que são trazidos à consciência do leitor, ouvinte, telespectador ou internauta. Nesta relação entre quem ditará as regras do conteúdo que passa nos media, no ambiente que nos propomos analisar - os media e as instituições políticas, a agenda mediática em consonância ou não com a agenda política - , o cidadão poderá (e opinam muitos deverá) ter a sua cota-parte de julgamento. Sousa, no seu ensaio "O jornalismo na democracia representativa", dá-nos dados que são relevantes para a discussão (no bom sentido da palavra, no sentido de debate) a que nos propomos com este trabalho: "quando questionados, numa sondagem Gallup (Janeiro de 2008) para o Fórum Económico Mundial, sobre a confiança que detêm nos vários profissionais, os portugueses apontam os políticos como os maus da fita" (SOUSA, 2009, p. 1). Não constitui surpresa. Do outro lado da barricada, "os portugueses confiam, hierarquicamente, nos professores, na polícia e nos militares e, em terceiro lugar, nos jornalistas" (SOUSA, 2009, p. 1). Se conjugarmos esta percepção com a opinião de João Marcelino exposta anteriormente neste ponto do trabalho, obtemos a verificação de que dois dos vértices do triângulo 'media cidadãos - instituições políticas' estarão mais unidos: os cidadãos com os media, estando depois as instituições políticas (vulgo, os políticos) isoladas a exercer o poder (ou alguns dos poderes, até porque, como já vimos, o jornalismo pode também ser visto como um poder).

\section{A personalização da política}

Grohmann e Ferreira são claros quando dizem que a literatura, tanto de Comunicação quanto de Ciência Política, "tem apontado, nos últimos anos, para um cenário de personalização da política, em que os partidos vão para o segundo plano da disputa eleitoral" (2008, p. 1). Ora isto acontecerá em eleições presidenciais ainda mais, porque, à partida, e apesar de o apoio de um partido ainda se mostrar bastante forte na eleição de um presidente em 
Portugal, conforme os resultados pós-25 de abril ainda mostram, o que é certo é que a figura do Presidente é claramente supra-partidária, o que poderá puxar ainda mais à personalização "desta" política - a das presidenciais e dos presidentes. Havendo sempre a tentativa de desideologização das candidaturas, "os meios de comunicação ganham crucial importância na construção das identidades políticas, com os candidatos muitas vezes representando personagens" (GROHMANN e FERREIRA, 2008, p. 1 ), quando não arquétipos, continuam os autores, chegando por vezes, de eleição para eleição, a haver a mudança de persona. Cavaco Silva, por exemplo, teve de o fazer: depois de primeiro-ministro em Portugal durante 10 anos, teve de aparecer perante o eleitorado português, onze anos depois, transfigurado, pronto perante a opinião pública para exercer um cargo diferente do que habituou o país. Este hábito foi sendo desconstruído, claro está, desde 1995, e a ideia de construção de candidato presidencial, segundo Salgado, terá começado a ser construída desde 1999 (mais concretamente no dia 6 de novembro), "ano que foi mencionada pela primeira vez a possibilidade de uma candidatura de Cavaco Silva às eleições de 2006" (SALGADO, 2010, p. 46).

Mesquita fala-nos, a propósito deste tema/tópico, mesmo de uma hiperpersonalização e psicologização da vida política: "os mecanismos de identificação com a figura do líder político prevalecem sobre as tentativas de racionalização argumentativa", e onde "a complexidade dos problemas dissolve-se em combates de chefes, centrados nas imagens dos líderes recriadas pela televisão" (MESQUITA, 2003, p. 98).

E a televisão mostra-nos líderes, mais do que as ações desses mesmos líderes. É a figura e suas características pessoais que mais ficam na mente dos cidadãos. É o que pensa Robert Dallek, biógrafo de John F. Kennedy, que ao jornal 'Público' do dia 20 de janeiro de 2011 (dia que marcou os 50 anos do discurso de tomada de posse do $35^{\circ}$ presidente dos EUA) disse: "Não me parece que as pessoas neste país [EUA] recordem grande coisa do que os presidentes fazem". Segundo Dallek as pessoas não se lembram que Theodore Roosevelt montou o sistema de parques nacionais e criou a 'Food and Drug Administration', não se lembram que ele construiu o canal do Panamá e negociou o fim da guerra russo-japonesa. "Acha que se lembram de que Woodrow Wilson criou o sistema da Reserva Federal?", perguntava o biógrafo de JFK, concluíndo depois que "O que elas se lembram [as pessoas] é alguma da retórica. O que lembram é 'a única coisa que devemos temer é o medo' de Franklin Roosevelt" ou da retórica de Kennedy. "Recordam-se dele, tão vital, tão atraente, tão carismático, tão prometedor" (DALLEK, 2011), que são características pessoais, próprias da tese de personalização cada vez mais notória espelhada neste trabalho.

Quem concorda com isto, remetendo-nos também para outros autores que concluíram pelo mesmo, é Lewis, Inthorn e Wahl-Jorgensen, quando no livro deles "Citizens or consumers?: what the media tell us about political participation" dizem que "studies have repeatedly shown that the coverage of 
politics is invariably about style, process and personality rather than the policy decisions that will actually affect people" (2005, p. 5), mostrando que foi a essa conclusão que chegaram os autores Jackson, Deacon, Golding e Billig, e Sussman. Mas atenção. Esta citação mostra-nos que a cobertura da política se presta a uma personalização da mesma. A cobertura. Ou seja, a agenda mediática tem em atenção esses aspectos do campo político. E a política? Terá aprendido a lidar com esse tipo de cobertura e terá começado a "jogar" o mesmo jogo? Quem ditou e dita as regras desse jogo?

Um dos critérios de noticiabilidade (ou valor-notícia) comumente aceite é efetivamente a personalização, na qual se previa que determinado acontecimento tem mais hipóteses de se tornar notícia quando o tratamento jornalístico possa ser efetuado com base nas histórias dos intervenientes - de preferência a história de uma das pessoas envolvidas, numa tentativa de criação de líderes, conforme notou Gans quando escreveu primeiro que "the news focuses on leaders" e depois quando afirmou que "when necessary, the news even helps to create leaders" (1980, p. 62); Gans não se referia só ao tratamento das notícias sobre a classe política, mas estas ideia assentam bem na problemática deste ponto do trabalho e muito em concreto na figura de líder que um Presidente ou candidato a Presidente transparece para o público dos media.

Mas essas histórias dos intervenientes, neste nosso caso, os candidatos políticos, afinal são relatadas de que forma? Sublinhando o quê? Segundo o que Pacheco Pereira escreveu no 'Abrupto', blogue pessoal, em março de 2003, consoante pudemos ler em artigo de Serrano (2006, p. 10):

Os agentes políticos são apresentados como centrados na sua ambição e na sua carreira e julgados pela performance que mostram na gestão dessa carreira. Essa gestão é essencialmente entendida como gestão mediática e gestão dos calendários, numa permanente procura da oportunidade ideal, e dá pouca atenção à substância política e ideológica da acção. Este tipo de julgamento da acção política pelo seu efeito mediático valoriza o papel do classificador-julgador, ele próprio.

Assim sendo, aparece-nos como importantes fatores na personalização crescente dos políticos nas campanhas, entre outros, a história de vida de cada um dos candidatos (presidenciais, por exemplo), mesmo que essa história possa ser vista pelo cidadão como uma história de ambições pessoais, conforme opinou Pacheco Pereira. Marina Costa Lobo, que entrevistamos para este nosso trabalho", disse-nos que "a forma como nós fazemos as nossas escolhas políticas é emotiva, ou seja, eu gosto daquele candidato porque ele me inspira confiança". E porque é que ele inspira confiança? Porque "ele

\footnotetext{
${ }^{1}$ Entrevista concedida a Renato Pinto Ferreira, em Lisboa (no Instituto de Ciências Sociais da Universidade de Lisboa), no dia 9 de fevereiro de 2011.
} 
preenche uma série de requisitos mentais que eu tenho sobre o que para mim é uma pessoa de confiança". E depois entrou na campanha que analisamos neste trabalho para especificar alguns pontos e nos contextualizar:

\begin{abstract}
Pode ser uma pessoa de direita, conservadora, que não fala muito, ou pode ser uma pessoa como Manuel Alegre que tem um passado de muito activismo social, ou mesmo como Fernando Nobre que diz que não é de esquerda nem de direita e que tem um papel importante na sociedade em termos de trabalho na AMI, etc. Estes factores pessoais que nós identificamos como sendo importantes são eles próprios políticos. Os candidatos não são importantes por razões mediáticas superficiais. Os candidatos, no meu entender, os candidatos são importantes porque eles representam opções políticas. Eles próprios, os seus percursos, sinalizam o que eles fariam perante questões políticas e isso é o que leva as pessoas a votarem neles ou não. Nesta campanha apareceu o Manuel Alegre a dizer que defende o Estado Social e portanto "Votem em mim", o Cavaco a dizer que vai ser activo e que no fundo começou a tentar posicionar-se contra o Governo... Há uma personalização mas ela não é o que se pensa que ela é.
\end{abstract}

Um dos fatores chave neste discurso da politóloga, investigadora do Instituto de Ciências Sociais em Lisboa, é o de que a história de um candidato ("e quando nós falamos de eleição presidencial há claramente uma personalização") pode configurar indícios para o eleitorado do que determinada figura faria se ocupasse o lugar para o qual se candidata.

\title{
5. Gráficos e tabelas dos resultados da análise categorial dos jornais
}

Os três jornais diários portugueses referidos e analisados neste artigo são os seguintes: 'DN' - Diário de Notícias - jornal fundado em 1864 e atualmente pertencente ao grupo 'Controlinveste Media' (tiragem média diária em 2010 de 30 mil exemplares); o 'i' - fundado em 2009, vencedor do prêmio máximo da 'Society for News Design' em Fevereiro de 2011 como jornal com "o melhor design do mundo" (em 2010 tiragem média diária de 10 mil exemplares); e o 'Público' - fundado em 1990, pertencente ao Grupo Sonae de Belmiro de Azevedo, sendo atualmente o único diário português (dos pagos) tendo como diretora uma mulher, Bárbara Reis (tiragem média em 2010 de 34 mil exemplares).

As eleições decorreram no dia 23 de janeiro de 2011 e tiveram como vencedor Aníbal Cavaco Silva, que assim prolongou a sua estadia no 'Palácio de Belém' por mais 5 anos, uma vez que ele foi o candidato-Presidente, concorrendo novamente ao cargo. 
Total de notícias analisadas dos 3 jornais (do dia 10 a 21 de janeiro de 2011) - 217

Categorias presentes nos jornais e quantificação das mesmas:

Jornal ' $i$ ' - Total de notícias - $\underline{54}$

Títulos

$$
\begin{aligned}
& \text { Estudos - } 0 \\
& \text { Temas - } 29 \\
& \text { Campanha - } 11 \\
& \text { Combate - } 21 \\
& \text { 'Leads' } \\
& \text { Política - } 19 \\
& \text { Estudos - } 1 \\
& \text { Temas - } 27 \\
& \text { Campanha - } 15 \\
& \text { Combate - } 16 \\
& \text { Política - } 14
\end{aligned}
$$

Jornal 'Público' - Total de notícias - $\underline{67}$

Títulos

$$
\begin{array}{ll} 
& \text { Estudos - } 0 \\
& \text { Temas }-31 \\
& \text { Campanha }-15 \\
& \text { Combate }-30 \\
& \text { Política - } 23 \\
\text { 'Leads' } & \\
& \text { Estudos }-1 \\
& \text { Temas }-29 \\
& \text { Campanha - 26 } \\
\text { Combate }-23 \\
\text { Política - 21 }
\end{array}
$$

Jornal 'DN' - Total de notícias - $\underline{96}$ Títulos

$$
\begin{aligned}
& \text { Estudos - 4 } \\
& \text { Temas }-42 \\
& \text { Campanha - 38 } \\
& \text { Combate - 39 } \\
& \text { Política - } 27 \\
& \text { 'Leads' } \\
& \text { Estudos - 2 } \\
& \text { Temas - 35 } \\
& \text { Campanha - 39 } \\
& \text { Combate - 31 } \\
& \text { Política - 24 }
\end{aligned}
$$


Gráfico 1 - Contabilização das categorias nos 'Títulos'

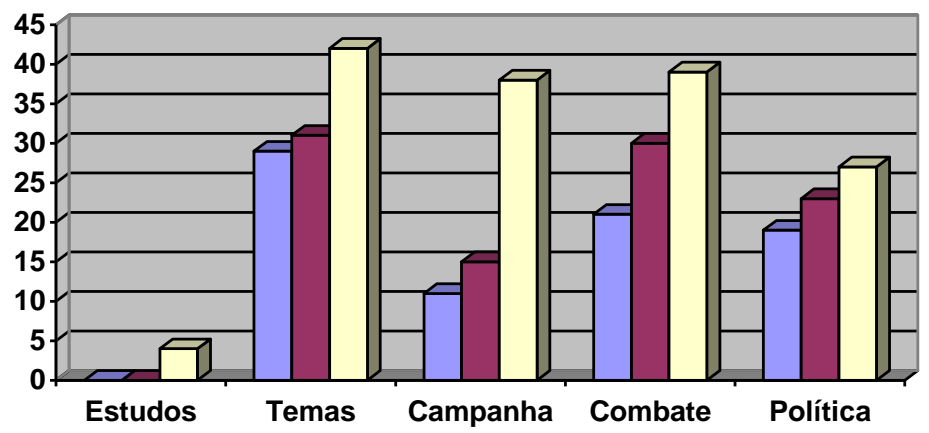

Fonte: Elaboração própria.

Gráfico 2 - Contabilização das categorias nos 'Leads'

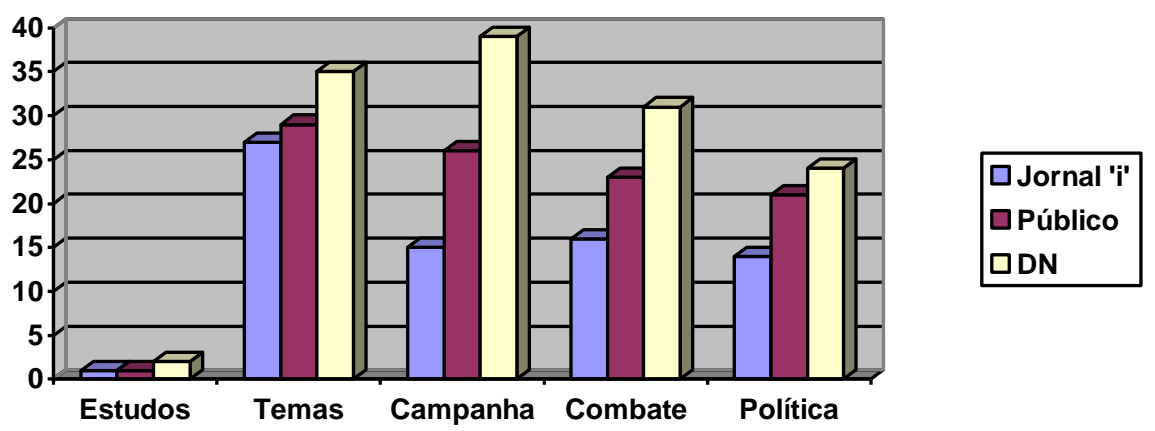

Fonte: Elaboração própria.

\section{Discussão de resultados}

Apesar de a nossa hipótese "desejar" que a categoria 'Combate' fosse a mais utilizada pelos jornalistas na construção das notícias, a verdade é que esse dado não se verifica. Verifica-se, isso sim, que a categoria 'Combate' é das mais utilizadas nos três jornais, ficando ou em segundo lugar ou em terceiro, quer nos títulos quer nos leads. Constatamos, mesmo assim, que o confronto (a horizontalidade), apesar de não ser a vertente mais utilizada por estes jornalistas destes jornais, é fator muito utilizado e uma referência que fica por vezes à frente da 'Campanha' - em tempos de campanha - e sempre à frente da Política - tratando-se de políticos.

A categoria 'Temas' é uma das características de um acompanhamento 'vertical', que se opõe ao 'Combate'. 'Política' e 'Campanha' serão também traços de 'verticalidade'. Assim sendo, a horizontalidade não é um fator tão 
destacado quanto a nossa hipótese fazia crer, embora seja uma presença constante.

Ainda de relevar a quase inexistência de notícias, respeitantes à campanha de cada um dos 6 candidatos presidenciais, que tenham como base de construção os 'Estudos', ou seja, sondagens que, apesar de terem saído em bom número durante as Presidenciais, não mereceram destaque nos títulos nem nos 'leads' das notícias.

Assim sendo, quanto aos títulos, nos três jornais a categoria que serviu de base à construção imaginativa desses mesmo títulos foi a categoria 'Temas', o que denota uma preocupação em trazer para a opinião pública os "issues", ou seja, os assuntos que interferem efetivamente, em princípio, com toda a dinâmica do país. Esta realidade noticiosa estudada vai efetivamente contra a nossa hipótese inicial.

Quanto aos '/eads', o 'Diário de Notícias' dá um maior destaque à campanha (o que se compreende - no início de uma notícia escrever-se sobre o 'Onde' estavam os candidatos; no fundo explicar ao leitor do que é que se estava a escrever naquela notícia, e no fundo era de campanha que se tratava); o 'i' destaca os 'Temas'; e o 'Público' sublinha no início das notícias os 'Temas' também. O que dissemos em relação aos títulos tem que ser repetido em relação aos leads, no que à constatação da verificação da nossa hipótese diz respeito.

\section{Conclusão}

Partimos da teoria de que o acompanhamento jornalístico neste jornais era 'horizontal', estando nós já preparados para propor uma maior 'verticalidade'. Esta proposição é válida, extrapolando ou utilizando indução, para todos os media no que se refere à cobertura da política. Verificamos contudo que, pelo menos neste pequeno estudo, a 'horizontalidade' não é assim tão destacada da 'verticalidade', e que ambos partilham um mesmo espaço neste media em particular. Em futuro artigo daremos conta do que se passou nos telejornais durante as Legislativas 2011 em Portugal, para solidificarmos a refutação ou corroboração da nossa teoria inicial consubstanciada na nossa hipótese inicial.

Podemos no entanto, em jeito final de 'arrumação' da nossa teoria, dizer que nela cabem dois modelos de acompanhamento possíveis do Jornalismo à Política: o 'horizontal' - com confronto feito pelos próprios agentes políticos das ideias uns dos outros; e o 'vertical' - na qual os media desenvolvem e pormenorizam as visões de País (com explanação das medidas concretas para chegarmos a essas idealizações) de cada um dos candidatos, deixando-se o confronto/comparação para a mente dos cidadãos eleitores e comentadores políticos/opinion makers. A verdade, existindo, é que podemos de certa forma estanquizar estes dois tipos de acompanhamento, que se acompanham numa teoria em que esses dois modelos disputam o espaço nos media, com vitória muito difícil de julgar - perante este nosso estudo. A 
propor algo, poderíamos propor que a 'horizontalidade' baixasse em detrimento de uma maior 'verticalidade', que será mais construtivo e edificante para cada um dos membros do País - cada um de nós - e para o País como um todo.

Uma das formas da sociedade estar atenta ao jornalismo que se faz, é termos um jornalismo que fale de si próprio. Ao acontecer isto, o quarto poder vigiará os outros três e a si próprio, numa auto-crítica construtiva de garantia de que os jornalistas estão a contar histórias (a isso não fogem...), mas histórias reais. Ou o mais reais possíveis. Será essa a função do jornalismo, que se quererá sempre mais pedagógico e formativo de cidadãos que se preocupam com a 'parte' - a sua própria vida - e o 'todo' - a vida do país e do mundo. O contar histórias, até como vimos na contextualização teórica deste artigo, prende-se muito na espécie de corrida entre agentes políticos (bastante emocional) e menos na explicação racional dos assuntos da vida pública; mas a componente prática aqui vista diz-nos que pelo menos os jornais tentam equilibrar essas duas formas de acompanhamento jornalístico que preconizamos (propomos) neste trabalho.

Seria (será) interessante comprovar com a análise de telejornais portugueses, se algo parecido acontece na televisão e jornalismo que nela se faz - esse trabalho está a ser feito no âmbito da nossa tese de doutoramento, o que permitirá uma maior amplitude de resultados para comparar. Mas também seria interessante - e lançamos o repto a investigadores de todos os países que se movem nesta área - comparar com resultados colhidos em outros países para uma maior reflexão nesta teoria dos dois acompanhamentos (horizontal e vertical) que aqui propomos enquanto modelo que nos permita compreender como os media (aqui só os jornais) retratam a vida política - entenda-se nesta frase e neste trabalho, os 'media' como o 'jornalismo' que se faz neles.

Renato Ferreira Licenciado e Mestre em Ciências da Comunicação pela Universidade Fernando Pessoa, no Porto, Portugal, é desde 2010 Doutorando em Ciências da Informação na mesma Universidade.

E-mail: renatopintoferreira@gmail.com

Ricardo Jorge Pinto é Licenciado em Jornalismo pela Escola Superior de Jornalismo (Porto, Portugal) e Doutor em Ciências da Informação pela University of Sussex, no Reino Unido. Docente na Faculdade de Ciências Humanas e Sociais da Universidade Fernando Pessoa, no Porto, Portugal. E-mail: ricpinto@ufp.edu.pt 


\section{Referências}

BARRIGA, Antónia do Carmo Anjinho. Media, Política e Opinião: uma tríade complexa. 2007. Disponível em: <http://www.b-on.com>. Acesso em: 30 dez. 2010.

CARVAlHo, Manuel Proença. Manual de Ciência Política e sistemas políticos e constitucionais. Lisboa: Quid Juris Sociedade Editora, 2010.

DALLEK, Robert. Kennedy - popular, apesar de tudo. Público, Lisboa/Porto, 20 jan. 2011, P2, p. 4-5.

FERNANDES, António José. Introdução à Ciência Política - teorias, métodos e temáticas. Porto: Porto Editora, 2008.

GANS, Herbert. Deciding what's news: a Study of CBS Evening News, NBC Nightly News, Newsweek and Time. New York: Random House, 1980.

GROHMANN, Rafael do Nascimento; FERREIRA, Rodrigo Toledo Tafuri. Os personagens televisivos e a personalização da política nas eleições de Juíz de Fora em 2008. 2008. Disponível em:

<http://www.intercom.org.br/papers/nacionais/2009/resumos/R4-0926-

1.pdf >. Acesso em: 21 out. 2010.

INNERARITY, Daniel. A transformação da política. Lisboa: Editorial Teorema, 2002.

LEWIS, Justin; INTHORN, Sanna; WAHL-JORGENSEN, Karin. Citizens or consumers: what the media tell us about political participation. 2005. Disponível em: <http://books.google.pt>. Acesso em: 14 abr. 2011.

MARCELINO, João. O balanço de uma iniciativa, DN, 15 jan. 2011, p. 11.

MESQUITA, Mário. O quarto equívoco - O Poder dos media na sociedade contemporânea. Coimbra: MinervaCoimbra, 2003.

NOVAIS, Jorge Reis. Semipresidencialismo - Teoria do sistema de governo semipresidencial. Coimbra: Almedina, 2007. v. 1

OLIVEIRA, Madalena M.C. Metajornalismo...Ou quando o jornalismo é sujeito do próprio discurso. 2007. Disponível em:

<http://repositorium.sdum.uminho.pt/bitstream/1822/7035/1/TESE-

FINAL.pdf>. Acesso em: 25 out. 2010.

RIEFFEL, Rémy. Sociologia dos Media. Porto: Porto Editora, 2003. 
SALGADO, Susana. A comunicação do poder ou o poder da comunicação. 2005. Disponível em:

<http://www.revistas.univerciencia.org/index.php/mediajornalismo/article/vie wFile/6190/5614>. Acesso em: 12 fev. 2011.

. Os Veículos da Mensagem Política. Lisboa: Livros Horizonte, 2007.

. Os candidatos presidenciais - Construção de imagens e discursos nos media. Coimbra: MinervaCoimbra, 2010.

SERRANO, Estrela. A dimensão política do Jornalismo. 2006. Disponível em: $<$ http://comunicacaoecultura.com.pt/wpcontent/uploads/2010/07/02_03_Estrela_Serrano.pdf>. Acesso em: $13 \mathrm{fev}$. 2011.

SOUSA, Jorge Pedro. A teoria do agendamento e as responsabilidades do jornalista ambiental: uma perspectiva ibérica. 2008. Disponível em: <http://www.bocc.ubi.pt/pag/sousa-jorge-pedro-teoria-doagendamento.pdf>. Acesso em: 19 jan. 2011.

O jornalismo na democracia representativa: um ensaio. 2009. Disponível em: <http://www.bocc.ubi.pt/pag/bocc-o-jornalismo-sousa.pdf>. Acesso em: 20 jan. 2011.

Texto recebido em 27/07/2011.

Aprovado em 20/11/2011. 